\title{
Para administrar a fé em Deus: ofertas de interfaces entre mídia, business e religião no Brasil
}

\author{
Managing Faith in God: Interfaces Among Media, Business and Religion in \\ Brazil
}

\section{Para administrar la fé en Dios: Interfaces Entre Mídia, Business y Religión en Brasil}

Paulo Celso da Silva ${ }^{1}$

Miriam Cristina Carlos Silva ${ }^{2}$

Luiz Guilherme Leite Amaral

\section{Resumo}

Este artigo aborda o momento contemporâneo analisando o site de Ensino a distância IPED (2015), com seu curso de Ensino Religioso abrangendo o Velho e o Novo Testamentos e os cursos complementares, considerados pelos responsáveis pelo site como importantes e relevantes para os interessados no tema. Entre eles encontramos curso de como administrar uma igreja. Partindo de autores como Harvey, Pross, Baitello Jr., Benjamin e Foucault, a pesquisa apresenta as interfaces possíveis entre mídia e religião, trata dos Espíritos Cotidianos, estes fragmentários e imediatistas de um presente intenso; o capitalismo 24/7 como culto e narrativa para encaminhar uma conclusão que recoloca o próprio corpo nesse modo de produção cada dia mais informacional e sem pausas.

Palavras-chave:Mídia. Religião. Business. Contemporaneidade.

\section{Abstract}

This article discusses the contemporary days by analyzing the site of Distance Education IPED (2015) away with their Religious Education course regarding the Old and the New Testaments and other complementary courses, considered by the website owners as relevant for those interested in the topic. Among them we find the Church Administration couse. Starting from authors such as Harvey, Pross, Baitello Jr., Benjamin and Foucault, the research shows the possible interfaces between media and religion; deals with Everyday Spirits, these fragmentary and immediate element of an intense present; 24/7 capitalism as worship and storytelling forward to a conclusion that relocates the body itself in this mode of production, increasingly informational day and without pauses.

Keywords: Media. Religion. Business. Contemporary.

\begin{tabular}{|c|c|}
\hline \multirow{3}{*}{ 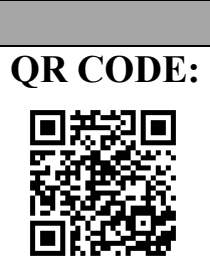 } & Acesse este artigo online \\
\hline & $\begin{array}{l}\text { Website: } \\
\text { http://www.revistas.ufg.br/index.php/ci }\end{array}$ \\
\hline & $\begin{array}{l}\text { DOI: } \\
\text { http://dx.doi.org/10.5216/ci.v19i2.3663 } \\
2\end{array}$ \\
\hline
\end{tabular}

\section{Resumen}

Este artículo aborda el momento contemporáneo analizando el website de Ensino a Distancia IPED (2015), con su

\footnotetext{
${ }^{1}$ Doutor em Geografia (Geografia Humana) pela Universidade de São Paulo (USP). Mestre em Geografia (Geografia Humana) pela USP e Pós doutoramento pela Universitat de Barcelona. Graduação em Geografia pela Faculdade de Filosofia Ciências e Letras de Sorocaba e em Filosofia pela Faculdade de Filosofia Ciências e Letras de Sorocaba. E-mail: paulo.silva@prof.uniso.br

2 Pós doutorado em Comunicação Social pela Pontifícia Universidade Católica do Rio Grande do Sul (PUC-RS). Doutor e Mestre em Comunicação e Semiótica pela Pontifícia Universidade Católica de São Paulo (PUC-SP). Graduação em Licenciatura Plena em Letras - Português / Inglês pela Universidade de Sorocaba (UNISO). E-mail: miriam.silva@prof.uniso.br

${ }^{3}$ Mestrando em Comunicação e Cultura pela Universidade de Sorocaba (UNISO). Graduação em Comunicação Social pela Escola Superior de Administração, Marketing e Comunicação de Sorocaba (2007). E-mail: luiz.amaral.mestrado@gmail.com
}

Comun. \& Inf., Goiânia, GO, v. 19, n. 2, p. 19-34, jul./dez. 2016. 
curso de Educación Religiosa que se compone del Antiguo IPED (2015) el Nuevo Testamento IPED (2015) cursos complementarios de formación, considerada por los propietarios del sitios web como importante IPED (2015) relevantes para los interesados en el tema. Entre ellos encontramos el Curso de Como Administrar una iglesia. A partir de autores como Harvey, Pross, Baitello Jr., Benjamin IPED (2015) Foucault, la investigación muestra las posibles interfaces entre medios de comunicación IPED (2015) religión; se ocupa de los Espíritus Cotidianos, éstos fragmentarios IPED (2015) de inmediatista de un presente intenso; el capitalismo 24/7 como culto IPED (2015) narración para proponer, hacia adelante, una conclusión que reemplaza el cuerpo mismo en este modo de producción, cada día más informacional IPED (2015) sin pausas.

Palabras clave: Medios de Comunicación. Religión. Business. Contemporaneidad.

\section{INTRODUÇÃ̃O}

m 1989, no esforço de compreender o momento pelo qual passava o mundo,
David Harvey afirma a condição pós-moderna em curso desde inícios da
década de 1970, a qual configurava e reconfigurava não apenas a economia política (em sentido estrito) mas toda vida cultural do globo. A maneira como indivíduos passaram a se relacionar com coisas e pessoas vai acumulando outras possibilidades com a inclusão, cada vez maior, de aparatos tecnológicos à vida cotidiana. $\mathrm{O}$ mesmo autor analisa, assim, como espaço e tempo são experimentados com esses novos aparatos e suas racionalidades.

No bojo das "novidades" gestadas e desenvolvidas nos anos seguintes, a filosofia, questionando racionalmente o mundo em busca de caminhos para um Eu totalizado e/ou totalizante, vê-se diluída e abstraída e não procura mais a emancipação secular por meio da razão, tecnologia e ciência,trazendo à tona uma crise moral na qual estes três pilares, desde o Iluminismo, ofereceram mais à opressão e morte, ao mesmo tempo em que negavam a verdade de Deus. Isto porque, "a luxúria e o poder são 'os únicos valores que não precisam da luz da razão para serem descobertos" (Baltimore Sun, 9 de setembro de 1987), como afirmava Rocco Buttiglione (HARVEY, 1989, p. 47).

Dessa forma, a verdade de Deus é racional e pode ser afirmada, ou seja, utilizando um discurso racional, inclusive imagético, e não totalizante, desconstruímos outras formas racionais totalizantes desenvolvidas pela modernidade. A fragmentação é instituída como possibilidade analítica, substituindo as metanarrativas pelas quais o modernismo deu sentido à sociedade. Na teologia pós-moderna, a fragmentação pode ser representada pela mudança do paradigma: de uma (moderna) religião do medo para uma (pós-moderna) religião do amor (DEWEY apud RORTY, VATTIMO, 2006, p. 23) sem que a Santíssima Trindade seja isolada, ou seja, do uno para a tríade que, no limite, é una também.

Comun. \& Inf., Goiânia, GO, v. 19, n. 2, p. 19-34, jul./dez. 2016. 
No plano da vida prática, uma complexa somatória de atividades são capitalizadas, buscando oferecer alternativas, sempre e sabidamente por todos como precárias, pois a efemeridade, a descontinuidade e as mudanças caóticas pós-modernas conformam a tônica do viver de parcelas da população, ou, como aqui chamados, dos "espíritos cotidianos".

Podemos aqui denominá-los assim como representantes da religião capitalista, como analisava Benjamin,quando considerava o capitalismo como uma "religião de mero culto, sem dogma" no qual o "espírito fala na ornamentação das notas" (BENJAMIN, 2011, p. 3). Neste contexto, analisamos um dentre os múltiplos sites de "Educação Religiosa"existentes online, refletindo sobre as ofertas indicadas aos "espíritos cotidianos" sobre o ensino religioso na utilização da mídia terciária e, em menor medida, na escolha de cores e imagens para atrair e vender os produtos.

\section{A INTERAÇÃO SOCIAL E A APRENDIZAGEM}

A interação social, desde o século XIX, tornou-se uma matéria que ganhou produção muito rica no meio acadêmico (ARANHA, 1993). Várias escolas contribuíram para a sistematização deste fenômeno e ainda hoje se mostram bastante influentes para questionar as problematizações advindas deste processo. Autores como Hinde, Macoby e Martin dão foco ao relacionamento familiar enquanto Vygosky e Leontiev buscam dar consistência aos seus estudos em meio a uma União Soviética que não possui hierarquia social e religião.

Um fato, porém, emerge em comum: as relações sociais são um fenômeno que produzem "contínuo movimento dialético de influência entre parceiros interativos (...) como um contexto em que se dá a construção, por um lado, da subjetividade humana e, por outro, da própria história da humanidade" (ARANHA, 1993, p. 25). Isto significa que a construção do tecido social e de inter-relacionamentos só começa a fazer sentido enquanto os indivíduos geram um produto a partir das relações entre si. Mais ainda, evidencia o quão importante se torna o reconhecimento e sistematização das interações sociais para uma unidade social que produza características próprias. De acordo com Vygotsky (apud ARANHA, 1993), "a estrutura humana complexa é o produto de um processo de desenvolvimento profundamente enraizado nas ligações entre a história individual e história social".

Nas religiões, a figura do sujeito interativo como alguém que constrói e garante a validade do ato religioso também faz parte de um processo de interação social, desta vez abarcando nestas interações os intuitos e intenções que são particulares às motivações da própria doutrina religiosa em que estão contidos. Isto porque o sujeito interativo não modifica somente a estrutura social na qual ele está, mas também reflete na mudança do comportamento

Comun. \& Inf., Goiânia, GO, v. 19, n. 2, p. 19-34, jul./dez. 2016. 


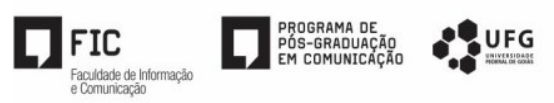

de todos que estão expostos às suas ações. Em outras palavras, é compreensível que exista esta relação de troca uma vez que o aprendizado - e mais adiante a repetição ou adaptação do que é aprendido - está cumprindo seu papel de amálgama neste sistema de inter-relações.

Hinde (apud ARANHA, 1993, p.23) constrói uma correlação entre o conteúdo e sua qualidade na construção da relação de aprendizagem entre indivíduos. A equação "A faz x para B e B faz Y para A" mostra que o aprendizado e a interação não estão restritos apenas a um processo de repetição, mas que existe um processamento e transformação das ideias quando confrontadas com uma situação em particular. De acordo com este raciocínio, é confortante entender que o processo de aprendizagem está mais relacionado a mecanismos profundamente conectados em nós do que a meras técnicas que por vezes trazem-nos desconfiança.

Alia-se à interação social e aprendizagem os modelos de comunicação, sobretudo os baseados em meios eletrônicos, para compor um raciocínio de como o IPED (2015) está aninhado a uma gama de técnicas e fundações que a permitem construir o modelo de ensino e por que não de negócios - que propõe em seu site. Esta alteração no ambiente relacional acaba por movimentar-se no sentido de acoplar as teorias desenvolvidas outrora para um momento de abundância de recursos eletrônicos.

Alguns autores, porém, podem discutir a questão do termo comunicação no ensino a distância enquanto se prendem ao modelo clássico de canais, mensagem e interação entre as partes. O que podemos averiguar aqui, no entanto, é que a utilização de diversos componentes que suprem as faltas do relacionamento pessoal acabam também por preencher as lacunas destes modelos clássicos. Compreende-se que uma aula do IPED (2015) é baseada em a) um vídeo, que emula o aluno estar em frente ao professor; b) um módulo de bate-papo, que simula a conversa entre aluno e professor; e c) um repositório de documentos, que representa a bibliografia proposta pelo curso. Isto nos leva a crer portanto, que existe a interação social mesmo quando é calcada nas mídias terciárias de Pross. A interação, a troca de mensagens e a absorção de conteúdo que é apreendido e depois transformado, conforme mencionado anteriormente seguindo o modelo equacional de Hinde, não deixa dúvidas quanto à completude do raciocínio proposto nesta discussão.

Analisar o ensino e aprendizado a distância requer uma constante viagem no tempo e no espaço. O trabalho de pesquisa requer contato constante com autores que desenvolveram seus trabalhos em diversas épocas diferentes. Da década de 1920 saltamos facilmente para a década de 70; da extinta União Soviética vamos à França sem mesmo chegar perto de um avião.

Comun. \& Inf., Goiânia, GO, v. 19, n. 2, p. 19-34, jul./dez. 2016. 
E, como acontece neste caso, foram feitas viagens sem qualquer tipo de dispositivo - apenas livros.

Aqui encontra-se um estudo comparativo e calcado em diversos autores de diferentes áreas, mas todos convergem de alguma forma para o ensino a distância. Quando olhamos para as contribuições de Leibniz, fazemos correlações com Foucault na medida em que ambos conseguem desvendar mistérios de assuntos semelhantes e que trazem as mesmas inquietações à mente. Este comparativo também se faz verdadeiro na utilização de outros autores das teorias sociais críticas. São ideias que, quando colocadas lado a lado, criam um mapa para que seja possível tatear os meandros de um assunto tão fascinante.

Prosseguimos, assim, na viagem ao tempo a partir da produção científica de tantos autores: Harvey, Pross, Vattimo, etc. São nacionalidades, tempos e escolas diferentes, porém é surpreendente como o conhecimento atravessa fronteiras e, a partir do repertório e análise singulares de cada um dos autores, a resolução de questões atuais já havia sido apresentada. Impossível não pensar em Mozart, que disse "as notas musicais estão lá; eu só preciso colocálas na ordem correta”. A teorias já estão presentes; precisamos aplicá-las ao problema correto.

\section{ESPÍRITOS COTIDIANOS (GEIST ALLTAG)}

A perspectiva do viver na pós-modernidade incluiu para as populações a possibilidade de ter a sensação dos múltiplos espaços e tempos ocupados ou, pelo menos, indicados e demarcados por meio de redes, aplicativos de smartphones, tablets e suas variantes. Diante disso, podemos recorrer ao conceito de Heterotopia, desenvolvido por Michel Foucault, no qual encontramos as inúmeras e fragmentadas camadas que se relacionam com outros lugares, e o filósofo francês afirma, dentre as várias formas de Heterotopia, o quinto princípio quedescreve exatamente a ritualística:

Fifth principle. Heterotopias always presuppose a system of opening and closing that both isolates them and makes them penetrable. In general, the heterotopic site is not freely accessible like a public place. Either the entry is compulsory, as in the case of entering a barracks or a prison, or else the individual has to submit to rites and purifications. To get in one must have a certain permission and make certain gestures (FOUCAULT, 1984). ${ }^{4}$

\footnotetext{
${ }^{4}$ Quinto princípio. Heterotopia sempre pressupõe um sistema de abertura e fechamento que tanto as isola como as torna penetráveis. Em geral, o local heterotópico não é livremente acessível como um local público. Ou a entrada é obrigatória, como no caso de entrar em um quartel ou uma prisão, ou então o indivíduo tem de submeter-se a ritos e purificações. Para entrar [nos rituais] deve-se ter uma certa permissão e fazer certos gestos. FOUCAULT, Michel. "Of Other Spaces, Heterotopias." Architecture, Mouvement, Continuité 5 (1984): 46-49. Disponível também em inglês e francês em $<$ http://foucault.info/doc/documents/heterotopia/foucault-heterotopia-en-html $>$ Acesso em 06 mai. 2015.
}

Comun. \& Inf., Goiânia, GO, v. 19, n. 2, p. 19-34, jul./dez. 2016. 
Assim posto, a igreja é considerada uma heterotopia ritualística, na qual os espíritos cotidianos são entendidos como aquela substância incorpórea que forma uma outra camada na qual a efemeridade, a descontinuidade e as mudanças caóticas são assumidas diariamente. Também podemos pensar os espíritos cotidianos em um sentido mais teológico, seguindo a sugestão de Leibniz, na obra Monadologia ( 82,83 ss), quando afirma que "os espíritos ou almas racionais são imagens da Divindade (...) é o que faz com que os Espíritos sejam capazes de entrar numa espécie de sociedade com Deus" (LEIBNIZ apud LALANDE, 1996, p. 327). Entretanto, essas "imagens da Divindade" servem a diferentes entidades fragmentárias e efêmeras no seu dia a dia. E o capitalismo é o seu culto.

Examinando mais detidamente o cotidiano, este pode ser entendido como o locus da imediatez e das atitudes repetitivas e, de certa forma, também da não reflexão. A necessidade da rapidez nas respostas que a praticidade exige emum cotidiano revestido de técnicas e tecnologias nos remete a Lefebvre, que afirmou:

$\mathrm{Na}$ sociedade em que vivemos é certo que a técnica adquire um caráter dominante (...) Através da imagem e do objeto (e do discurso sobre a imagem e sobre o objeto), a consciência, social e individual,refletem a técnica (...)o olhar sobre o objeto técnico, olhar passivo, atento apenas ao funcionamento, interessado somente pela estrutura (desmontagem, remontagem), fascinado por esse espetáculo sem segundo plano, completo, na sua transparente superfície, esse olhar torna-se protótipo do ato social. Tal é a eficácia da televisão. O meio, isto é, o aparelho, é a verdadeira mensagem, afirma McLuhan. Não. A mensagem é o puro reflexo: o olhar sobre uma imagem, o olhar que se produz e reproduz enquanto relação social, olhar frio (cool) dotado, nesse sentido de um feedback, de um equilíbrio, de uma coerência, de uma perpetuação. As imagens mudam, o olhar permanece. Os ruídos, os sons, as palavras são auxiliadores e subsidiários, símbolos do efêmero (LEFEBVRE, 1991, p. 57).

Mas, o feedback, se é equilíbrio e coerência, também é provisório, momentâneo e define a vida cotidiana e, portanto, também é passível de "desequilíbrios ameaçadores" (LEFEBVRE, 1991, p. 39), criando o movimento por meio da dialética do viver. No mundo pós-moderno de que falamos, parte disso se repete, haja vista que as temporalidades não são as mesmas para todos os espaços. Temporalidades que se comprimem na proposta ideológica do viver, conectar, trabalhar em " $24 / 7$ ” cotidianamente, isto é, vinte e quatro horas por dia durante os sete dias da semana. É a cotidianeidade intensa vivida como "presente puro e não relacionado no tempo", como sugeria Jameson (1996, p. 80) décadas atrás e hoje implica em que "No momento, a operação e os efeitos particulares de novas máquinas ou redes específicas são menos importantes do que a redefinição da experiência e da percepção pelos ritmos, velocidades e formas do consumo acelerado e intensificado"(CRARY, 2014, p. 48).

Comun. \& Inf., Goiânia, GO, v. 19, n. 2, p. 19-34, jul./dez. 2016. 
Com isso, os espíritos cotidianos atuais são fragmentários, conectados no presente imediato, talvez instantâneo, das experiências cotidianas. Em outras palavras, "Tempo sem espera, de uma disponibilidade instantânea, de permanecer isolado na presença dos outros"(CRARY, 2014, p. 133).

\section{O CAPITALISMO COMO CULTO E NARRATIVA}

Retomando as reflexões de Benjamin quando relacionava e comparava o capitalismo ao cristianismo, o primeiro como uma "religião de mero culto, sem dogma", já citado anteriormente, indicava que o capitalismo busca satisfazer os usuários/clientes/consumidores e tirar-lhes das preocupações, dramas e desesperos que anteriormente eram da alçada das religiões. $\mathrm{O}$ autor reconhece três traços que asseguram a estrutura religiosa do capitalismo. São eles:

Primeiro, o capitalismo é uma religião puramente cultual, talvez a mais extrema que jamais tenha existido. Nada há nele senão uma relação imediata com o significado do culto; ele não conhece nenhum dogma especial nem teologia. O utilitarismo ganha, sob esse ponto de vista, sua coloração religiosa. Um segundo traço do capitalismo interliga-se com esta concreção do culto: a duraçãopermanente do culto. O capitalismo é a celebração de um culto sans rêve et sans merci [sem sonho e sem piedade]. Não há nele nenhum "dia de semana", nenhum dia que não seja de festa no sentido terrível do desdobramento de toda pompa sagrada, da tensão extrema do adorador.

Em terceiro, este culto é culpabilizador [verschuldend]. O capitalismo é provavelmente o primeiro caso de um culto não expiatório, mas sim culpabilizador [verschuldenden] (BENJAMIN, 2011, p. 2).

Atualizando o culto capitalista, vemos um acréscimo do adjetivo smart a (quase) tudo relacionado às tecnologias informacionais sem nos darmos conta de que os aparatos nos conectam e integram cada vez mais profundamente ao $24 / 7 \mathrm{e}$, portanto, para o culto ininterrupto da religião capitalista, reforçando os traços citados por Benjamin e potencializando, exponencialmente, o segundo. $\mathrm{O}$ mesmo podemos considerar quanto ao terceiro traço, a culpa.

Não produzir ou deixar de produzir propositadamente trazia a culpa do ócio consciente. Faltar por faltar ao serviço equivalia a, praticamente, um pecado. Na sociedade 24/7, não responder a um Whatsapp imediatamente ou não curtir uma postagem nas redes sociais quebram a cadeia do automatismo dos gestos e traz, para muitos, a sensação de dever não cumprido, de estar em falta mais com o aparato que com a pessoa do outro extremo da interação. Temos assim uma uniformidade generalizada, a qual não cria indivíduos semelhantes mas atua pela redução/eliminação das diferenças (CRARY, 2014,p. 64).

Nesse contexto de redes sociais e mídias filtrantes das experiências cotidianas,

Comun. \& Inf., Goiânia, GO, v. 19, n. 2, p. 19-34, jul./dez. 2016. 
mescladas com narrativas em imagens ou 140 caracteres, o culto capitalista invade um reduto extremo onde "ele não conhece nenhum dogma especial nem teologia", a saber,o próprio ensinamento cristão.

\section{UMA INTERFACE ENTRE MÍDIA E RELIGIÃO}

Para comprovarmos empiricamente o que estamos falando desde o início sobre o capitalismo como religião e culto, buscamos um site que oferece cursos grátis e pagos a distância. Dentro da gama oferecida está o de Ensino Religioso, como se pode observar na Figura 1:

Figura1 - Oferta de cursos on line grátis e pagos

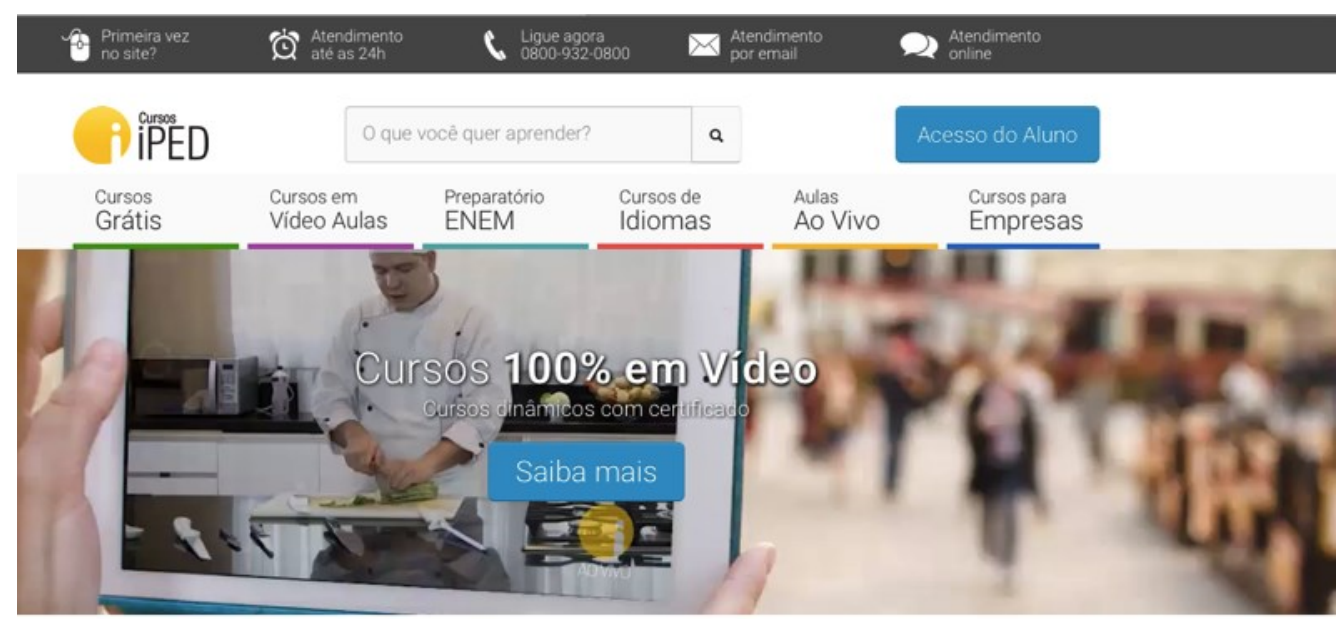

\section{Mais de 1000 opções de cursos grátis com certificado}

Inscreva-se nos próximos Cursos Online Grátis:

Fonte: $<$ https://www.iped.com.br/login $>$

A empresa dos Cursos IPED (2015) - Instituto Politécnico de Educação a Distância foi criada em 2001 com a visão de "Qualificar 1 milhão de estudantes gratuitamente até 2014", e tem a Missão de "Gerar oportunidade para as pessoas entrarem em um mundo de conhecimento e qualificação profissional. Para nós é mais do que um compromisso, é um prazer" (IPED, 2015). O aluno pode interagir com o material e os professores por meio de Atendimento 24 horas, "Ligue agora 0800", E-mail e atendimento online, e o material "é elaborado por conteudistas, professores e pesquisadores das mais renomadas instituições em diversas regiões do Brasil”".

Ainda, conforme o site, “O grupo é formado pelas seguintes unidades de negócios: Cursos Profissionalizantes, Cursos para Crianças, Cursinho Preparatório para Vestibular,

Comun. \& Inf., Goiânia, GO, v. 19, n. 2, p. 19-34, jul./dez. 2016. 
Cursos Preparatórios para Concursos Públicos e Planos Corporativos”. E aposta, como diferencial, na tecnologia de ponta de que o grupo dispõe, assim como em seu potente Data Center (IPED, 2015).

Dentre as quinhentas opções de cursos, encontramos o de Ensino Religioso.

Figura2 - Opções do ensino religioso

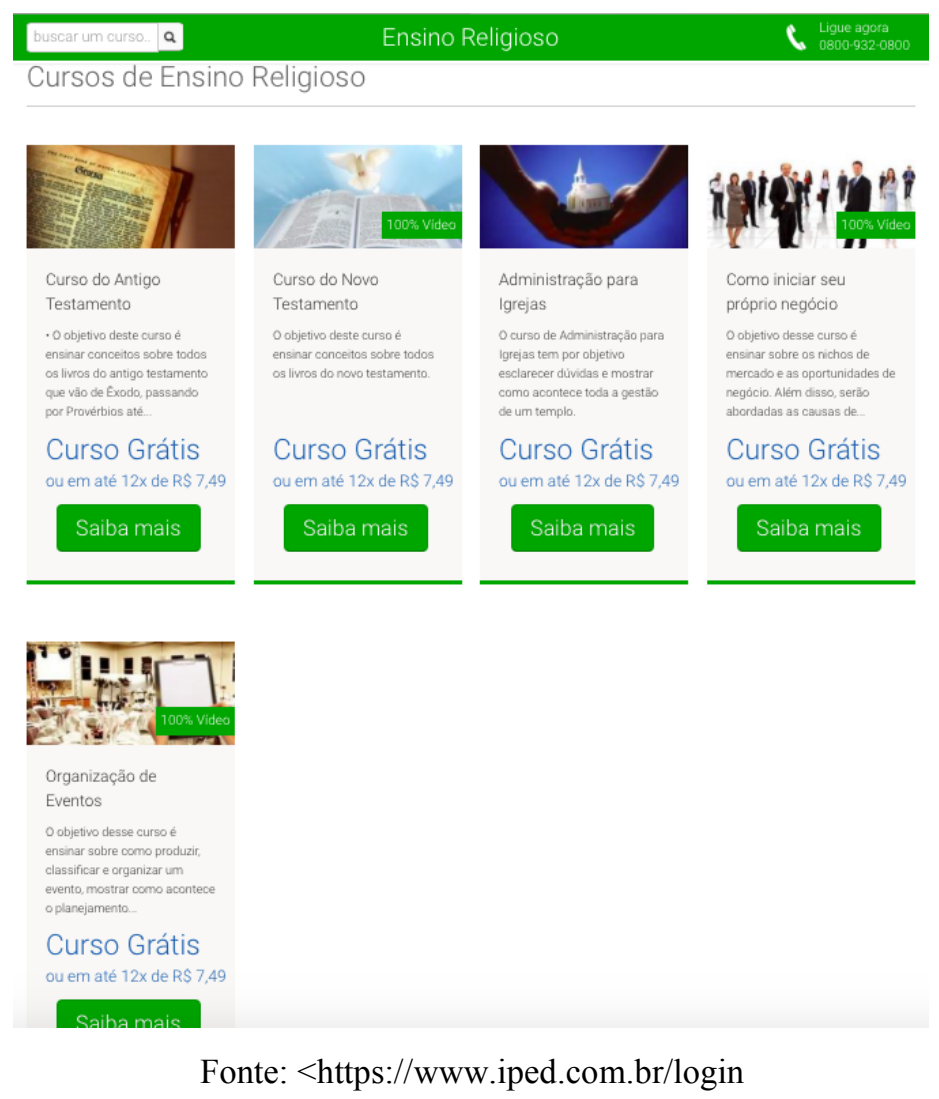

Na Figura 2 podemos observar a sequência linear da oferta dos cursos. Ou seja, iniciase com o Velho Testamento (20h), Novo Testamento (20h), Administração para Igrejas (20h), Como Iniciar seu Próprio Negócio (20h) e finaliza com Organização de Eventos (20h). Em 100 horas de curso, o aluno perpassa o Velho e o Novo Testamentos, tornando-se apto a iniciar a evangelização, ainda que em uma escala amadora quando comparado a teólogos graduados e/ou pós-graduados. O passo seguinte é aprender a administrar igrejas para que sejam autossustentáveis e rentáveis. De posse desse conhecimento, é hora de aprender as artimanhas dos empreendedores de sucesso. A etapa final é organizar e promover eventos, conhecimento necessário para a mobilização e encantamento dos seguidores - momento de congregação dos fiéis com Deus.

Vale dizer que 100 horas de aulas equivalem, na maioria dos cursos, a um ano de estudos semanais, ou duas horas de aula nas cinquenta e duas semanas que tem o ano. Ainda que o curso seja gratuito, é necessário um investimento no tempo de dedicação, manter o foco

Comun. \& Inf., Goiânia, GO, v. 19, n. 2, p. 19-34, jul./dez. 2016. 
nos objetivos pessoais e do curso, disciplina para o estudo diário, ler os textos, procurar sites dos temas e assistir aosvídeos. Evidentemente, o curso oferece "doses de entusiasmo" e também "cobranças e lembretes dos objetivos traçados", utilizando a tecnologia de bate-papo, e-mail ou telefone. $\mathrm{O}$ aluno não fica solitário em sua empreitada. $\mathrm{O}$ site também oferece informações adicionais acerca do Ensino Religioso, como podemos ver na Figura 3:

Figura3 - Informações adicionais

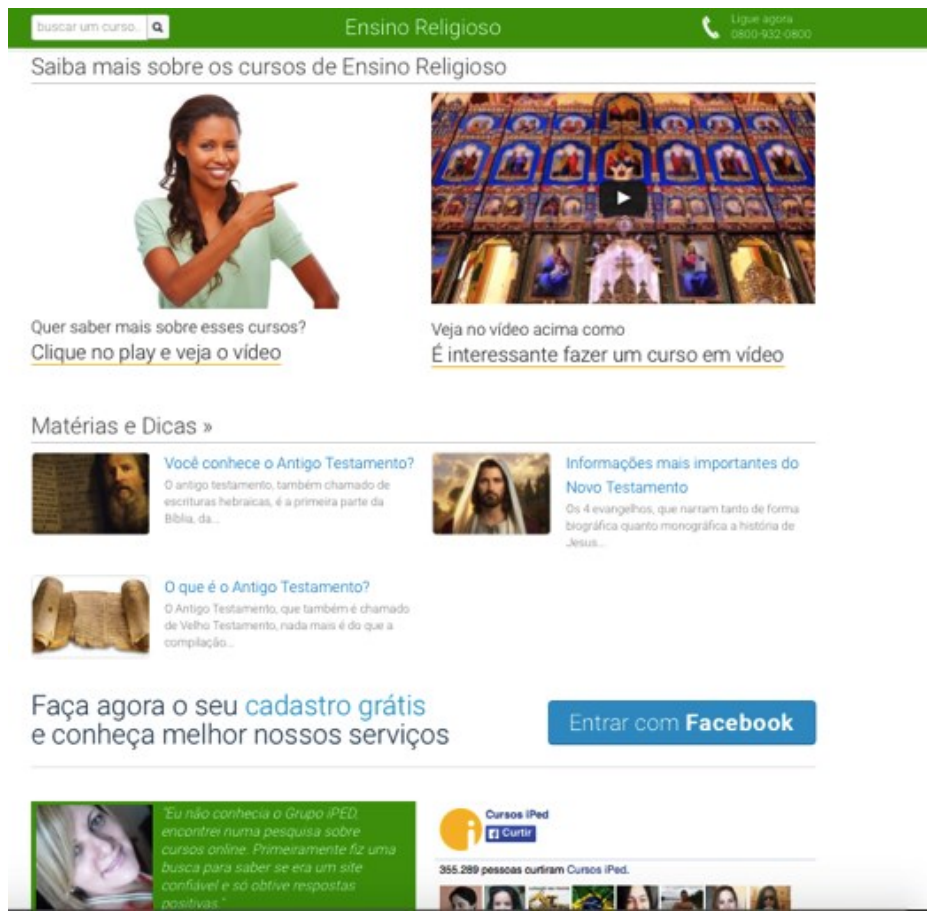

Fonte: $<$ https://www.iped.com.br/login

\section{O PROCESSO TRANSMIDIÁTICO DO IPED}

Cumprir o curso de Ensino Religioso da plataforma IPED (2015) faz com que ocorra um processo elíptico de utilização das mídias secundária e terciária. Se por um lado as vídeoaulas cumprem a proposta de aceleração do tempo e redução de espaço, conforme aponta BAITELLO JR. (2001), também encontramos, amparados em JENKINS (2009), um processo transmidiático quando se está satisfatoriamente comprometido com o curso oferecido em questão.

A mídia terciária está evidente pelo uso da eletricidade, do computador, dos provedores e servidores ao acessar a plataforma. Apenas isso já nos basta para compreender o que Pross (apud BAITELLO JR., 2001) nos ensina com relação a este aspecto comunicacional. O processo elíptico começa a surgir, no entanto, quando da utilização do material didático proposto pelo IPED (2015). Baixar um texto no formato PDF de uma aula continua na esfera da mídia terciária, porém, ao imprimi-lo e tê-lo em mãos para leitura ou consulta, o estudante

Comun. \& Inf., Goiânia, GO, v. 19, n. 2, p. 19-34, jul./dez. 2016. 


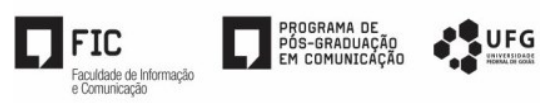

agora faz uso de uma mídia secundária para cumprir seus objetivos, cuja origem se deu em uma mídia terciária.

Este jogo de "vai-e-vem" entre as duas mídias é a proposta do IPED (2015) por tratarse de um método de estudo, indo ao encontro do que Jenkins (2009) aponta como um processo de transformação cultural, que está incutido no grau de comprometimento de quem o utiliza. É possível perceber quecada um dos cursos propostos e ilustrados na Figura 2 exige duas coisas: que o estudante tenha o material didático - baixado e impresso ou em livro - a postos e a disponibilidade de assistir às aulas em vídeo. Os cursos de Velho e Novo Testamentos exigem que o aluno tenha acesso a uma Bíblia impressa, que possa fazer anotações, marcadores e completar os exercícios propostos. Isso é evidenciadono momento em que o professor que ministra a aula no vídeo revela todas estas particularidades.

$\mathrm{O}$ processo transmidiático utilizado para descrever como se desenvolvem as "narrativas transmidiáticas" pode ser empregado também neste caso pela sua similaridade técnica. As narrativas transmidiáticas propõem que uma história sobre qualquer assunto ouduração seja construída a partir da utilização de diversos meios, como livro, cinema, internet, etc. No caso do curso a distância, a linearidade do conteúdo é construída a partir da utilização dos recursos propostos no programa. Isso quer dizer que chegar ao final do curso a distância faz com que a "história" se complete. O fato de possuir uma bibliografia evidencia este processo, bem como a exigência de que os textos e exercícios produzidos a partir das aulas sejam amparados pelas matérias e lições que são divulgadas nos vídeos.

O contato pessoal e verbal entre professor e aluno é entendido como mídia primária, que na plataforma IPED (2015) se dá a partir de salas de bate-papo, e aí transmuta-se novamente para a mídia terciária, pelo fato de termos os mesmos suportes iniciais que a configuram, segundo Pross (1971). Aqui, novamente, o comprometimento do aluno com o curso é o que define a utilidade da mídia. Se não há quem utilize a sala de bate-papo para tirar dúvidas, ela não tem uma razão para estar disponível no portal. Este caso, no entanto, está mais distante do padrão elíptico promovido pela plataforma e não se encaixa como uma transmutação; está mais próximo a uma substituição,se não total, em quase sua totalidade.Desta forma, percebe-se que se efetivará uma transformação bastante significativa: a ausência do contato entre corpos.

Tanto nos processos educacionais quanto nos rituais religiosos convencionais, ocorre a utilização da mídia primária - um corpo em contato com outros corpos. A experiência se dá no contato entre esses corpos, com trocas de gestos, odores, tato, sensações relacionadas ao ambiente (frio, calor), sons. A experiência é tridimensional e requer a partilha imediata, de um

Comun. \& Inf., Goiânia, GO, v. 19, n. 2, p. 19-34, jul./dez. 2016. 
tempo e um espaço comuns, o que exige um acordo de disponibilidade e intenções coletivas. Ao migrar para as mídias secundária (corpo / aparato tecnológico / corpo) e terciária (corpo / aparato / aparato / corpo), opera-se com a bidimensionalidade e a nulodimensionalidade. Elimina-se o rito. O ambiente e o tempo passam a ser negociados isoladamente. Ao invés de múltiplos corpos em contato, comunhão e conflito, opera-se com o corpo isolado do sujeito em busca de sua própria formação, independentemente de outros corpos. Aciona-se a experiência isolada. E mesmo quando ocorre a troca em chats: a negociação se dá a partir do interesse isolado do indivíduo, que terá o conteúdo desejado disponível a partir do momento em que acionar a tecla Power de seu aparato mediador. Passa-se não apenas à formação, mas a própria religiosidade como experiência imanente, e não transcendente. E se é possível buscar a própria formação em qualquer uma das 24 horas do dia, trata-se de mais um elemento para compor o 24/7 e alimentar a tônica de um capitalismo cotidiano.Daí não causar nenhum espanto que a formação religiosa assemelhe-se a qualquer outra formação mercadológica.

Entretanto, há que se pesar a visão de Baitello Jr. (2012), que parece convergir para a ideia de um corpo $24 / 7$ conectado às máquinas que nos fazem permanecer ativos o tempo todo. O pesquisador das mídias alerta para o quanto a sociedade contemporânea buscou uma vida sedentária, ofertada "pela cultura racional, letrada e escolarizada" (BAITELLO JR, 2012, p. 18). E salienta que o decréscimo de mobilidade do corpo resulta em um decréscimo do pensar, "de sua imprevisibilidade, de sua sempre ativa criatividade e de sua capacidade de... surpreender " (idem). Assim:

Viver sentado é uma mudança radical de vida, uma negação da inquietude do saltador e do incansável caminhante. Significa assentar e acalmar o andarilho inquieto, sedar a sua necessidade de movimento e sua capacidade de apreender (que significa agarrar) o que lhe cerca, de explorar curiosamente o mundo, de reagir ao entorno, de saltar de ideia em ideia. Sentados, estamos anestesiados, sedados (BAITELLO JR, 2012, p. 21).

Os cursos de Administração de Igrejas, Como Iniciar seu Próprio Negócio e Organização de Eventos também exigem bibliografia que seja impressa, previamente ou a partir do repositório da plataforma, e assiduidade nas aulas gravadas em vídeo, e o resultado disto é a criação de um conteúdo programático que premia o processo transmidiático para alcançar os objetivos do programa. Apesar de serem oferecidos em módulos separados, fica clara a intenção de criar uma linha de pensamento que certifica as reflexões de Benjamin (2001) acerca do capitalismo como religião.

Pode-se observar também como a mídia secundária é tomada como tão importante se não mais - que a mídia terciária pelo IPED (2015) quando menciona a impressão e envio de

Comun. \& Inf., Goiânia, GO, v. 19, n. 2, p. 19-34, jul./dez. 2016. 
um certificado de conclusão de curso. É inegável lembrar do que Baitello Jr. (2001) reflete sobre isto:

Por outro lado, com a mídia secundária inauguram-se a permanência e a sobrevida simbólicas após a presença do corpo. Com a escrita e seus precursores (as imagens gravadas sobre suportes duráveis) impõe-se o homem sobre a morte e seu tempo irreversível, vencendo simbolicamente seu maior e mais poderoso adversário. O grande trunfo da escrita não é, portanto, a velocidade, mas a lentidão que permite cifrar e decifrar enigmas. $\mathrm{O}$ tempo lento da escrita e da leitura permite alongar a percepção do tempo de vida (BAITELLO JR, 2001, p. 5).

O certificado autentica, autoriza e pereniza a formação ofertada pelas mídias secundárias e terciárias. Parece que a sociedade das redes ainda requer autorização da mídia secundária, a sociedade da escrita. E a escrita também é a referendação do mundo erudito, formalizado e acadêmico.

É compreensível que a pós-modernidade que vivemos proporcione com que o método de ensino da plataforma IPED (2015) faça com que os alunos saltem de uma mídia para outra de uma forma seamless, jargão amplamente empregado no meio tecnológico para definir algo que não sofre interrupções, que é feito sem sentir mudanças. Vai-se do vídeo ao impresso, do papel à tela em questão de segundos e com uma facilidade tal que a engenharia da computação nos faz até mesmo esquecer como isso era tão difícil de acontecer há menos de meio século.

A única diferença - e talvez a mais importante - é que se vai da tridimensionalidade para a bidimensionalidade, e para a nulodimensionalidade sem roçar-se outros corpos, mas com um corpo tomado por sedentarismo associado a um ativismo visual, nas palavras de Baitello Jr. (2001). Um ativismo visual 24/7, no qual o corpo se consome sem contato com outros corpos. O corpo que consome a si mesmo.

\section{CONCLUSÃO}

Este artigo abre caminhos para a compreensão do corpo que é afetado pela utilização das mídias, sobretudo por sua condição de corpo conectado $24 / 7$ enquanto aceita o que as plataformas computacionais têm a oferecer. Mas, ao mesmo tempo, também aceita que a escrita - o impresso - constitui um papel fundamental na perenização da ação da tela digital: o IPED (2015) educa a distância e é reconhecido como uma plataforma que cumpre seu papel, mas só é aceito com a chancela de um documento escrito.

Com uma metodologia que trabalha comparativamente as ideias de autores para que se possa construir mais conhecimento a respeito do fenômeno do ensino a distância, e respeitando a analogia sobre viagem no tempo e no espaço, conforme descrita no início deste

Comun. \& Inf., Goiânia, GO, v. 19, n. 2, p. 19-34, jul./dez. 2016. 
texto, foi possível entender como se dá o processo de interação social ainda que calcada em aparatos e como os módulos de um site desses pode preencher lacunas que não existem no contato direto e pessoal. Para a construção deste texto foi necessário ir à Alemanha, França, Espanha, de volta ao Brasil e várias indas e vindas, além de, claro, falar todos estes idiomas.

Abre também a discussão sobre como as diferentes mídias descritas por Pross (1971) complementam-se para constituir o objetivo da plataforma, que é a conclusão do curso, ao utilizar o vídeo, o impresso e emular o contato pessoal. O processo transmidiático proposto pelo IPED (2015) mostra que os meios de propagar o conhecimento não são excludentes, mas cooperativos, pelo fato de que a combinação de todos eles não apenas auxilia na chegada ao final do curso, mas também se torna avalisadora do comprometimento do aluno com a proposta. Enquanto houver público para assistir aos vídeos, completar as tarefas e compilar as leituras em um único compêndio que seja prático para os estudos, compreende-se o quão importante se torna esta transmutação das mídias secundária e terciária ao longo das 100 horas de exposição ao conteúdo programático do site.

Esta alternativa de estudos provoca alterações nas relações entre todos os envolvidos. Em uma sala de aula regular, há a troca de experiências entre professor e alunos, debates e diversos outros tipos de construção de identidade e anexação social. Pela plataforma de ensino do IPED (2015), todos estes fenômenos tentam ser reconstruídos a partir de ferramentas, como sala de bate-papo, envio de trabalhos, revisão de pares, entre outros. O que se nota, no entanto, é como a relação se torna rasa em função da nulidade do contato físico. O contato não é olho no olho, mas olho na câmera. Interromper o professor é apertar o botão Pause. Anotar o que está na lousa é anotar o que está na tela.

O sucesso da plataforma IPED (2015) está diretamente relacionado com a capacidade que seu público tem de aceitar esta nova forma de ensinar. Isto também está qualificado como um elemento de mudança de comportamento, pois se cria uma nova relação de autossuficiência, ou seja, por mais que a plataforma estabeleça critérios e prazos para a entrega das atividades, o senso de "punição" pelo não cumprimento torna-se mais abrandado, já que ainda é possível prosseguir no curso a distância. Não há diário de classe ou nota. Faz parte do jogo o aluno/consumidor introjetar esta consciência de que absorver o conteúdo oferecido só depende dele, ainda que ele enfrente menos barreiras.

O aluno, portanto, tem que passar a lidar com outros elementos que são próprios do ensino a distância: o corpo sentado e que recebe as informações em uma tela. O computador proporcionou ao estudante ir à sala de aula, à bibioteca e "socializar" com alunos e professores,

Comun. \& Inf., Goiânia, GO, v. 19, n. 2, p. 19-34, jul./dez. 2016. 
ainda que em um nível muito menos empolgante e instigante para o crescimento intelectual como ainda se observa necessário. A tela do computador, com o auxílio das impressoras 3D, também está muito próxima de emular outro momento corriqueiro no dia a dia de uma escola: ir a uma cantina e fazer uma refeição rápida.

Todos estes elementos são comuns em cursos oferecidos a distância, e já fazem parte do dia a dia de estudantes de distintas classes sociais e faixas etárias. Chama atenção, aqui no entanto, o conteúdo programático oferecido: ensino religioso. Alocado de forma não ritualizada, mas com uma identidade corporativista, este aprendizado remete à formação de um novo negócio - o negócio da fé. Não por acaso, no mesmo site, encontra-se também um curso de como administrar a sua igreja. A interface da educação a distâcia, com aspecto visual similar ao de qualquer interface mercadológica, institucional e corporativista, leva à religião como capital. Trata-se de mais um entre os inúmeros negócios/produtos de que a conexão 24/7 pretende oferecer aos usuários/consumidores.

\section{REFERÊNCIAS}

ARANHA, M. S. F. A interação social e o desenvolvimento humano. Periódicos eletrônicos em Psicologia, Ribeirão Preto, v. 1, n. 3, dez. 1993. Disponível em: $<\mathrm{http} / / /$ pepsic.bvsalud.org/scielo.php?script=sci_arttext\&pid=S1413389X1993000300004\&lng=pt\&nrm=iso>. Acesso em: 22 ago. 2015.

BAITELLO JR., N. O tempo lento e o espaço nulo. In: FAUSTO NETO, A. et al. (Org). Interação e sentidos no ciberespaço e na sociedade. Porto Alegre, EDIPUCRS, 2001. Disponível em: $<$ http://www.cisc.org.br/portal/index.php/en/biblioteca/finish/7-baitello-junior-norval/10-o-tempolento-e-o-espaco-nulo-midia-primaria-secundaria-e-terciaria.html>. Acesso em: 21 ago. 2015.

BAITELLO JR., N. O pensamento sentado: sobre glúteos, cadeiras e imagens. São Leopoldo: Unisinos, 2012.

BENJAMIN, W. Capitalismo como religião. Tradução de Jander de Melo Marques Araújo. Revista Garrafa 23, janeiro-abril 2011.

CRARY, J. 24/7 capitalismo tardio e os fins do sono. São Paulo: Cosac \& Naify, 2014.

IPED Quem somos. Disponível em: <https://www.ipedcom.br/sobre>. Acesso em: 10 jun. 2015.

FOUCAULT, M. Of other spaces, heterotopias. Architecture, mouvement, continuité. v. 5, p. 46-49, 1984. Disponível em <http://foucault.info/doc/documents/heterotopia/foucault-heterotopia-en-html $>$. Acesso em: 06 maio 2015.

HARVEY, D. The conditional of postmodernity. An enquire into the origins of cultural change. Basil Blackwell, 1989. Edição Brasiliera: Condição Pós-Moderna. São Paulo: Loyola, 1994.

JAMESON, F. Pós-modernismo: a lógica cultural do capitalismo tardio. São Paulo: Ática, 1996.

JENKINS, H. Cultura da convergência. São Paulo: Aleph, 2009.

LALANDE, A. Vocabulário técnico e crítico da filosofia. 2. ed. São Paulo: Martins Fontes, 1996.

Comun. \& Inf., Goiânia, GO, v. 19, n. 2, p. 19-34, jul./dez. 2016. 
LEFEBVRE, H. A vida cotidiana no mundo moderno. São Paulo: Ática, 1991.

RORTY, R.; VATTIMO, G. O futuro da religião: solidariedade, caridade e ironia. São Paulo: Relume Dumara, 2006.

Recebido em: 21/07/2015

Aceito em: 16/11/2015

Publicado em: $31 / 12 / 2016$

Comun. \& Inf., Goiânia, GO, v. 19, n. 2, p. 19-34, jul./dez. 2016. 